\title{
Thyroid Diseases in Omani Type 2 Diabetics: A Retrospective Cross-Sectional Study
}

\author{
Sanaa Al-Sumry, ${ }^{1}$ Thuraya Al-Ghelani, ${ }^{1}$ Huda Al-Badi, ${ }^{1}$ \\ Mohammed Al-Azri, ${ }^{2}$ and Kawther Elshafie ${ }^{2}$ \\ ${ }^{1}$ Oman Medical Specialty Board (OMSB), P.O. Box 745, 121 Seeb, Oman \\ ${ }^{2}$ Department of Family Medicine and Public Health, Sultan Qaboos University (SQU), Muscat, Oman \\ Correspondence should be addressed to Sanaa Al-Sumry; dr.shs@hotmail.com
}

Received 16 August 2015; Revised 27 October 2015; Accepted 24 November 2015

Academic Editor: Bernard Venn

Copyright (C) 2015 Sanaa Al-Sumry et al. This is an open access article distributed under the Creative Commons Attribution License, which permits unrestricted use, distribution, and reproduction in any medium, provided the original work is properly cited.

\begin{abstract}
Background. Diabetes mellitus and thyroid diseases are common endocrine disorders in the general population and found to exist simultaneously. This study aimed to establish the prevalence of thyroid dysfunction among Omani type 2 diabetics and its association with glycemic control. Methodology. A retrospective cross-sectional randomized primary and secondary care based study of 285 Omani type 2 diabetics, $\geq 30$ years of age with known thyroid function. The following parameters were examined: age, sex, duration of diabetes, duration of thyroid disease, thyroid morphology, thyroid function, thyroid antibodies, and the mean glycated hemoglobin (mean $\mathrm{HbAlC}$ ). The prevalence of thyroid dysfunction was compared to an independent control group of randomly selected healthy individuals with known thyroid function. Results. Thyroid dysfunction was found in $12.6 \%$ of the diabetic patients compared to $4.9 \%$ in the control group. The prevalence was higher among the diabetic females (86\%) compared to diabetic males (14\%). The commonest thyroid dysfunction among diabetics was overt hypothyroidism (4.6\%). Subclinical hypothyroidism was the commonest thyroid dysfunction seen in less controlled diabetics at a mean HbAlc of $7.8( \pm 0.7)$. Conclusion. Screening for thyroid dysfunction in patients with type 2 diabetes mellitus should be routinely performed considering the higher prevalence of thyroid diseases in this group compared to the general population.
\end{abstract}

\section{Introduction}

Diabetes mellitus (DM) and thyroid diseases (TD) are common endocrine disorders in the general population. According to the year 2014 statistics, the International Diabetes Federation (IDF) has estimated that around 387 million people are living with diabetes worldwide. Several countries of the Eastern Mediterranean Region (EMR) are among the top ten countries with the highest prevalence in diabetes. The regional prevalence is ranging from 7\% in Egypt to over 20\% in some of the Gulf Cooperation Council (GCC) countries [1].

The prevalence of diabetes varies between different populations. In Oman, diabetes has emerged as a major and growing health problem. The first national diabetes survey was conducted in 1991 and showed that the prevalence of diabetes in adults aged 20 years and over was $8.3 \%$.
Subsequent surveys showed that the prevalence is increasing and it reached $12.3 \%$ in 2008 [2].

Thyroid diseases are also common in the general population. There is a great difference in the prevalence of the thyroid diseases in the general population, ranging from $6.6 \%$ to $13.4 \%[3,4]$. Large scale studies of thyroid dysfunction in the United States have reported prevalence of $6.6 \%$ in the general population $[5,6]$. To the best of our knowledge, no studies have been conducted to evaluate thyroid dysfunction in Omani population.

The association between diabetes and thyroid disease is well known. The first studies were published in year 1997 [7]. Therefore, several studies in different countries were conducted to estimate the prevalence of thyroid disease in diabetic patients. Some studies estimated the prevalence to be $10-24 \%$ [8]. 
The strong association between diabetes and thyroid diseases encouraged the American Diabetes Association (ADA) to propose that people with diabetes must be checked periodically for thyroid dysfunction [9]. Thyroid disease should be screened annually in diabetic patients to detect asymptomatic thyroid dysfunction [10]. On the other hand, patients with thyroid dysfunction may need to be tested for the possibility of abnormal glucose metabolism, since excessive thyroid hormones cause increase in glucose production in the liver, rapid absorption of glucose through the intestine, and increase in insulin resistance [9].

Our aim in this study is to establish the association between diabetes mellitus and thyroid diseases in Omani population, to describe the morphology and the type of thyroid disease associated with diabetes mellitus, and to determine whether thyroid disease in diabetes mellitus is causatively associated with glycemic control. Based on the results of this study, the periodic screening for thyroid diseases in diabetics can be decided.

\section{Research Design and Method}

2.1. Subjects. This is a retrospective cross-sectional study conducted at Sultan Qaboos University Hospital (SQUH) which is a tertiary teaching hospital, in Muscat region in the Sultanate of Oman. A random sample of 500 Omani type 2 diabetics who had attended the endocrinology and the family medicine outpatient clinics between July 2010 and July 2011 were selected for the study. Their medical record numbers were obtained by the help of the hospital information system (HIS). The final number of the diabetic patients who fulfilled the inclusion and exclusion criteria was found to be 285 . A similar number of an independent control group was recruited for this study from SQU Health Center. The control groups were 288 nondiabetic healthy individuals, who had attended the abovementioned clinic for either minor medical problems or for routine medical checkup.

2.2. Inclusion and Exclusion Criteria. The inclusion criteria included were type 2 Omani diabetics of both sexes, whose age is equal or above 30 years and who were on antidiabetic treatment for at least one year. The exclusion criteria included non-Omani diabetic patients, type 1 diabetics, diabetics with unknown thyroid status, and newly diagnosed diabetics (duration $<1$ year).

The confidentialityof patients was maintained during the research. Patient's identifiers including names and hospital identification numbers were substituted by serial numbers. No new tests were carried out during the research.

Since the analysis of both groups is based on a preexisting data obtained from a previous research study, individual informed consent was not collected. However permission was obtained from the concerned department and the study was approved by the SQU ethical committee.

2.3. Measurement. The following parameters were collected using chart review: age, sex, duration of diabetes mellitus, duration of thyroid disease, thyroid morphology (based on clinical examination notes and/or radiological imaging), thyroid function, thyroid antibodies, and mean glycated hemoglobin (HbAlC), from the readings of the last 4 years.

2.4. Analytical Methods. Thyroid dysfunction was classified as clinical hypothyroidism (C-Hypo) if TSH levels were greater than $5.6 \mu \mathrm{UI} / \mathrm{mL}$ and free T4 (FT4) levels were lower than $7.9 \mathrm{pmol} / \mathrm{L}$ and/or free T3 (FT3) levels were less than $2.8 \mathrm{pmol} / \mathrm{L}$; subclinical hypothyroidism (SC-Hypo) if TSH levels were greater than $5.6 \mu \mathrm{UI} / \mathrm{mL}$ and FT4 and FT3 levels were normal; subclinical hyperthyroidism (SC-Hyper) if TSH levels were lower than $0.34 \mu \mathrm{UI} / \mathrm{mL}$ and FT4 and FT3 were normal; and clinical hyperthyroidism (C-Hyper) if TSH levels were lower than $0.34 \mu \mathrm{UI} / \mathrm{mL}$ and FT4 level is higher than $14.4 \mathrm{pmol} / \mathrm{L}$ and/or FT3 level is higher than $7 \mathrm{pmol} / \mathrm{L}$.

2.5. Statistical Analysis. Statistical analysis was done using Statistical Package for Social Sciences (SPSS 16). Mean \pm $\mathrm{SD}$ was determined for quantitative data and frequency for categorical variables. Independent test was performed in all continuous variables. Normal distribution of the data was checked before any $t$-test. Chi-square was used to analyze group difference for categorical variables. A $P$ value of $<0.05$ was considered significant.

\section{Results}

285 diabetic patients with mean age of $57( \pm 11.5)$ were examined, 93 males (32.6\%) and 192 females (67.4\%) in whom thyroid dysfunction was found in 36 patients $(12.6 \%)$ (14\% males and $86 \%$ females). Thyroid dysfunction was significantly higher in the female gender with $P$ value of 0.01 . Other baseline characteristics between the two groups such as the age, duration of diabetes mellitus, glycemic control, and the type of antidiabetic treatment were not significantly different between the two groups (with a $P$ value of $0.54,0.98$, 0.16 , and 0.164 , resp.) (Table 1 ).

Out of the diabetic patients with abnormal thyroid function, 18 (6.3\%) had overt hypothyroidism (16.7\% males and $83.3 \%$ females), 13 females (4.6\%) had overt hyperthyroidism, four females (1.4\%) had subclinical hypothyroidism, and one female had subclinical hyperthyroidism (0.4\%) (Figure 1). In addition, overt hypothyroidism was found at a mean age of 60 years $( \pm 3.5)$ and overt hyperthyroidism at a mean age of 55 years $( \pm 2.6)$. Subclinical hypothyroidism was found at a mean age of 59 years $( \pm 4)$ (Figure 2 ).

Thyroid morphology was found to be abnormal in 6 females of whom one had diffuse goiter $(0.4 \%)$, one had multinodular goiter $(0.4 \%)$, two had solitary nodule $(0.7 \%)$, and two had thyroidectomy $(0.7 \%)$. However, thyroid morphology was unknown in 156 (55.1\%) patients (33.3\% males and $66.7 \%$ females).

We also examined the association between thyroid dysfunction and diabetes control (defined by the mean HbAlc), in which we found that overt hypothyroidism was observed at a mean HbAlc of $7.6( \pm 0.5)$, overt hyperthyroidism at a mean HbAlc of $7.4( \pm 0.5)$, and subclinical hypothyroidism at a mean HbAlc of $7.8( \pm 0.7)$ (Figure 3 ). 
TABLE 1: Baseline characteristics of study subjects with or without thyroid dysfunction among type 2 diabetic patients aged $>30$ years.

\begin{tabular}{|c|c|c|c|c|}
\hline & $\begin{array}{l}\text { All samples } \\
n=285\end{array}$ & $\begin{array}{l}\text { Diabetic subjects without } \\
\text { thyroid dysfunction } n=249\end{array}$ & $\begin{array}{l}\text { Diabetic subjects with } \\
\text { thyroid dysfunction } n=36\end{array}$ & $P$ value \\
\hline Age (years) ${ }^{*}$ & $57.05 \pm 11.46$ & $56.89 \pm 11.36$ & $58.14 \pm 12.27$ & 0.54 \\
\hline \multicolumn{5}{|l|}{ Gender } \\
\hline Male $n(\%)$ & $93(32.6)$ & $88(35.3)$ & $5(13.9)$ & \multirow{2}{*}{0.01} \\
\hline Female $n(\%)$ & $192(67.4)$ & $161(64.7)$ & $31(86.1)$ & \\
\hline Duration of diabetes (years) ${ }^{* \#}$ & $11.29 \pm 7.94$ & $11.42 \pm 8.18$ & $10.38 \pm 5.97$ & 0.98 \\
\hline HGBA1C $^{* *}$ & $7.99 \pm 1.9$ & $8.05 \pm 1.9$ & $7.55 \pm 1.48$ & 0.16 \\
\hline \multicolumn{5}{|l|}{ Type of treatment $n(\%)^{* *}$} \\
\hline Diet & $7(2.5)$ & $5(2.0)$ & $2(5.6)$ & \multirow{4}{*}{0.28} \\
\hline OHA & $152(54.3)$ & $132(54.1)$ & $20(55.6)$ & \\
\hline Insulin & $58(20.8)$ & $48(19.9)$ & $10(27.8)$ & \\
\hline Insulin + OHA & $63(22.3)$ & $59(24.0)$ & $4(11.1)$ & \\
\hline \multicolumn{5}{|l|}{ HGBA1C + } \\
\hline Controlled $(<8)$ & $153(57.5)$ & $133(56.6)$ & $20(64.5)$ & \multirow{2}{*}{0.40} \\
\hline Uncontrolled $(>$ or $=8)$ & $113(42.5)$ & $102(43.4)$ & $11(35.5)$ & \\
\hline
\end{tabular}

${ }^{*}$ Data presented as mean $\pm \mathrm{SD},{ }^{*}$ nonparametric test, and ${ }^{* *}$ median value.

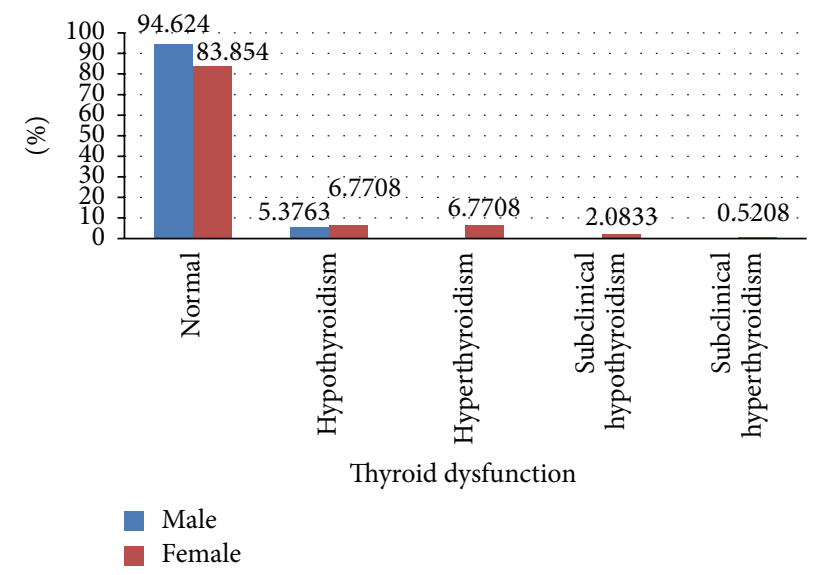

FIGURE 1: Distribution of thyroid dysfunction in Omani patients according to sex.

288 nondiabetic patients were selected as a control group to compare the prevalence of thyroid dysfunction with the diabetic subjects. The mean age of the control subjects was $46( \pm 8.4)$. This group includes 118 males $(41 \%)$ and 170 females (59\%). Thyroid dysfunction was found in 14 (4.9\%) patients, 7 males (50\%) and 7 females (50\%). Out of those patients, one female had hypothyroidism, three had hyperthyroidism (two males and one female), seven had subclinical hypothyroidism (four males and three females), and three had subclinical hyperthyroidism (one male and two females) (Table 2). Figure 4 represents the distribution of thyroid dysfunction among the diabetic and control group after age adjustment.

The mean age for thyroid dysfunction for this group was 40 years for overt hypothyroidism, 41 years for overt hyperthyroidism, 49 years for subclinical hypothyroidism, and 44 years for subclinical hyperthyroidism.

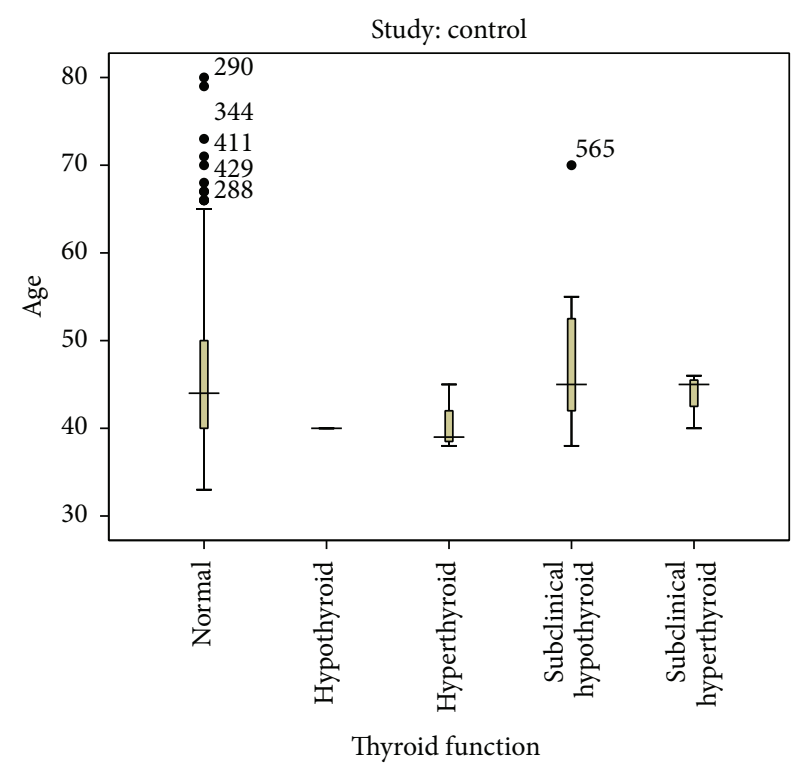

Figure 2: Distribution of thyroid dysfunction in the control group according to their mean age.

\section{Discussion}

This study demonstrates a $12.5 \%$ prevalence of thyroid dysfunction (TD) in the diabetic patients studied, which is three times higher than the control group in which the prevalence was only $4.9 \%$ (Figure 4 ). The prevalence in females was sixfold higher than the males in the study group while it is equal for both sexes in the control group. Our results are not much different from a Jordanian study in which the prevalence of thyroid dysfunction was $12.5 \%$ [11] and from a recent meta-analysis data in a study of 10920 patients with diabetes which revealed a mean frequency of thyroid disease 
TABLE 2: Baseline characteristics of the healthy nondiabetic control subjects.

\begin{tabular}{lc}
\hline Characteristic & $\begin{array}{c}\text { Control subjects } \\
(n=288)\end{array}$ \\
\hline Age $^{*}$ & $46 \pm 8.4$ \\
Gender & $118(41)$ \\
Males $n(\%)$ & $170(59)$ \\
Females $n(\%)$ & 4.9 \\
Thyroid dysfunction (\%) & 1 \\
Overt hypothyroidism & 3 \\
Overt hyperthyroidism & 7 \\
Subclinical hypothyroidism & 3 \\
Subclinical hyperthyroidism & \\
\hline
\end{tabular}

${ }^{*}$ Mean age \pm SD.

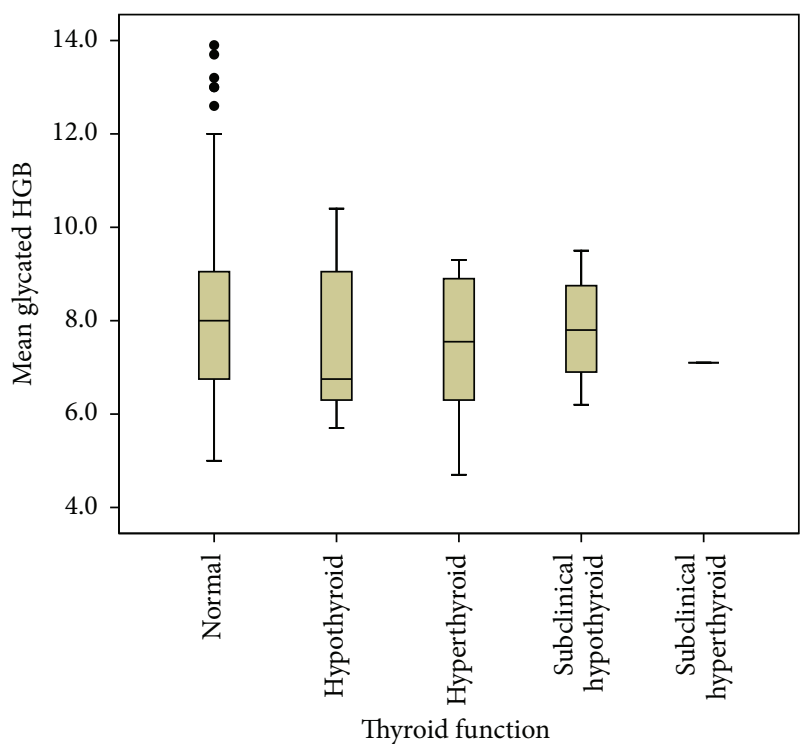

FIGURE 3: Distribution of thyroid dysfunction in diabetic patients according to their diabetic control (represented by the mean glycated HGB).

of $11 \%$. The data in type 1 diabetes (T1DM) did not differ from those in type 2 diabetes mellitus (T2DM) but the prevalence in females was consistently more than twofold that in males [10].

Hypothyroidism was the most frequent thyroid dysfunction found $(6.3 \%)$ corresponding to half of the percentage of TD among the study group which is $12.5 \%$ and accounts for more than sixfold the control group, while subclinical hypothyroidism was the most frequent thyroid dysfunction observed among the control group (2.4\%) with equal distribution among sexes. Akbar et al. reported a similar result in their study of Saudi T2DM patients in 2006 [12]. This indicates that diabetes was the main factor for the progression of thyroid disease from subclinical type which is predominant in the control group to overt hypothyroidism which was observed in the study group.

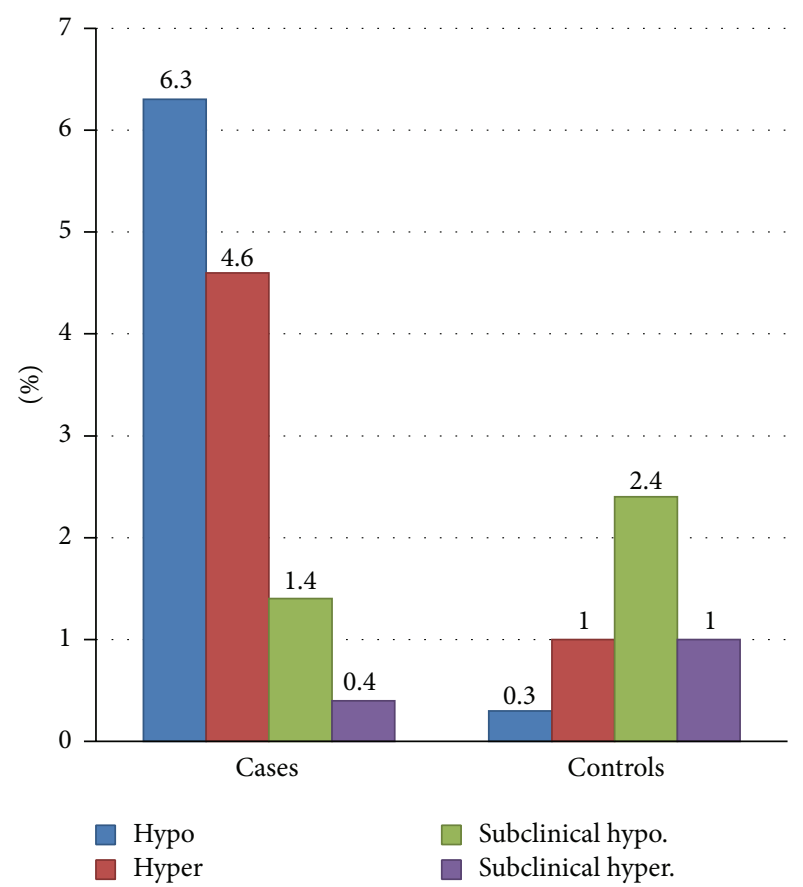

FIGURE 4: Distribution of thyroid dysfunction between the diabetics and the healthy controls.

In addition, a recent study done in Saudi Arabia reported a higher prevalence of thyroid dysfunction in Saudi type 2 diabetics reaching $28.5 \%$ of which $25.3 \%$ had hypothyroidism which was explained by the high prevalence of latent autoimmune diabetes of adults in the area reaching 26\% [13].

It is reported that DM appears to influence thyroid function in at least two sites, one at the level of hypothalamic control of thyroid stimulating hormone (TSH) release and the other at the conversion of thyroxine (T4) to $3,5,3^{\prime}$ triiodothyronine (T3) in the peripheral tissues [14].

Perros et al. reported that "the thyroid hormones, triiodothyronine (T3) and tetraiodothyronine (T4) are insulin antagonists that also potentiate the action of insulin indirectly." TRH synthesis decreases in diabetes, and this could be responsible for the occurrence of low thyroid hormone levels in diabetics [15].

In the literature, it is well known that thyroid hormones directly control insulin secretion, thus affecting the control of diabetes. In hypothyroidism, there is a reduction in glucoseinduced insulin secretion by beta cells, and the response of beta cells to glucose or catecholamine is increased in hyperthyroidism due to increased beta cell mass. Moreover, insulin clearance is increased in thyrotoxicosis [16, 17]. However, in our study, we failed to establish the association between thyroid disease and control of diabetes (represented by HbAlc), $P$ value 0.4 (Table 1 ). This can be explained by the other various factors that can play role in the control of diabetes including patients lifestyle, compliance to treatment, other used medications, and the duration of diabetes and thyroid disease.

There is little consensus on thyroid disease screening strategies in routine diabetes care and whether a specific 
screening policy is at all necessary in diabetic patients. The recommendations from some guidelines are vague with a lot of variation ranging from ignoring the thyroid function test to yearly testing [18]. Most of these recommendations apply to T1DM, whereas in T2DM thyroid screening is only recommended when an autoimmune disease is suspected by measuring thyroxin peroxidase antibody (TPOAb) and TSH in all diabetics at baseline, and then restrict subsequent unusual testing to only those patients with TIDM, positive antibodies, or TSH concentration in the upper range of normal [10]. It has been suggested that in the absence of definitive guidance local policies and practices are likely to remain discrepant [18].

The prevalence of TD in T2DM is almost comparable to that in T1DM, although the genetic links are less clear $[9,10]$. Therefore according to our findings we think that a routine screening for TD seems justified at least in high risk groups like patients above 50 years of age particularly with suggestive symptoms, raised antibody titer, or dyslipidemia. Our finding is similar to a lot of studies done for the screening of TD in patients with DM and most of them recommended screening routinely.

Unfortunately, 156 (55.1\%) of our diabetic patients had unknown thyroid morphology for which it was difficult to conclude its association with the antidiabetic treatment which was proved significant in the Turkish population [19].

In regard to the other factors examined, female gender was the only risk factor for developing thyroid dysfunction in our study, similar to the results in many other studies [11,20]. The duration and the control of diabetes were not significant factors for the development of TD. This could be explained by the shorter duration of the disease in our diabetics contrary to the abovementioned Saudi study in which the mean duration of diabetes was $15.8 \pm 8.6$ [13].

Some limitations in our study must be discussed. As our study is a retrospective cross-sectional study, the thyroid morphology was unknown in $55.1 \%$ of the sample group, for which we could not establish its association with diabetes. In addition, the thyroid gland imaging studies were not found in majority of the patients. For the same reason we were unable to study the effect of diabetes treatment on thyroid function and morphology. Other important confounders which could not be obtained were the family history of TD, smoking status, and the Body Mass Index (BMI) which were shown to be significant factors in the development of TD in other trials [13].

\section{Conclusion and Recommendations}

Thyroid dysfunction is common in type 2 diabetics compared to the general population in the Sultanate of Oman. This indicates that screening for thyroid function should be routinely performed. However, we suggest future observational studies to further explore the other risk factors for the development of thyroid dysfunction in diabetics. In addition, further studies are required on the cost effectiveness and frequency of screening for thyroid dysfunction in type 2 diabetic patients.

\section{Conflict of Interests}

The authors declare that there is no conflict of interests regarding the publication of this paper.

\section{Acknowledgments}

The authors would like to acknowledge the great assistance of the Department of Biochemistry at the Sultan Qaboos University (SQU) for helping with the sample used in the study. The authors also appreciate the great support of the Research and Statistics Department at the Oman Medical Specialty Board (OMSB).

\section{References}

[1] International Diabetes Federation, IDF Atlas Update, International Diabetes Federation, 6th edition, 2014.

[2] Diabetes Mellitus Management Guidelines, Ministry of Health, Muscat, Sultanate of Oman, 3rd edition, 2015.

[3] R. C. Silva, "Importância da avaliação da função tireoidiana em pacientes com diabetes mellitus," Arquivos Brasileiros de Endocrinologia \& Metabologia, vol. 49, no. 2, pp. 180-182, 2005.

[4] G. E. Umpierrez, K. A. Latif, M. B. Murphy et al., "Thyroid dysfunction in patients with type 1 diabetes," Diabetes Care, vol. 26, no. 4, pp. 1181-1185, 2003.

[5] G. J. Canaris, N. R. Manowitz, G. Mayor, and E. C. Ridgway, "The colorado thyroid disease prevalence study," Archives of Internal Medicine, vol. 160, no. 4, pp. 526-534, 2000.

[6] J. G. Hollowell, N. W. Staehling, W. Dana Flanders et al., "Serum TSH, $\mathrm{T}_{4}$, and thyroid antibodies in the United States population (1988 to 1994): National Health and Nutrition Examination Survey (NHANES III)," Journal of Clinical Endocrinology and Metabolism, vol. 87, no. 2, pp. 489-499, 2002.

[7] A. Papazafiropoulou, A. Sotiropoulos, A. Kokoloki, M. Kardara, and P. Stamataki, "e Pappas S: prevalence of thyroid dysfunction among greek type 2 diabetic patients attending an outpatient clinic," Journal of Clinical Medicine Research, vol. 2, no. 2, pp. 75-78, 2010.

[8] H. Gharib, R. M. Tuttle, J. Baskim, L. H. Fish, P. A. Singer, and M. T. McDermott, "Consensus statement. Subclinical thyroid dysfunction: a joint statement on management from the American Association of Clinical Endocrinologists, the American Thyroid Association and the Endocrine Society," Endocrine Practice, vol. 10, no. 6, pp. 497-501, 2004.

[9] J. L. Johnson, "Diabetes control in thyroid disease," Diabetes Spectrum, vol. 19, no. 3, pp. 148-153, 2006.

[10] R. Kadiyala, R. Peter, and O. E. Okosieme, “Thyroid dysfunction in patients with diabetes: clinical implications and screening strategies," International Journal of Clinical Practice, vol. 64, no. 8, pp. 1130-1139, 2010.

[11] A.-R. M. Radaideh, M. K. Nusier, F. L. Amari et al., "Thyroid dysfunction in patients with type 2 diabetes mellitus in Jordan," Saudi Medical Journal, vol. 25, no. 8, pp. 1046-1050, 2004.

[12] D. H. Akbar, M. M. Ahmed, and J. Al-Mughales, "Thyroid dysfunction and thyroid autoimmunity in Saudi type 2 diabetics," Acta Diabetologica, vol. 43, no. 1, pp. 14-18, 2006.

[13] M. Al-Geffari, N. A. Ahmad, A. H. Al-Sharqawi, A. M. Youssef, D. Alnaqeb, and K. Al-Rubeaan, "Risk factors for thyroid dysfunction among type 2 diabetic patients in a highly diabetes 
mellitus prevalent society," International Journal of Endocrinology, vol. 2013, Article ID 417920, 6 pages, 2013.

[14] Y. Suzuki, M. Nanno, R. Gemma, I. Tanaka, T. Taminato, and T. Yoshimi, "The mechanism of thyroid hormone abnormalities in patients with diabetes mellitus," Nippon Naibunpi Gakkai zasshi, vol. 70, no. 4, pp. 465-470, 1994.

[15] P. Perros, R. J. McCrimmon, G. Shaw, and B. M. Frier, "Frequency of thyroid dysfunction in diabetic patients: value of annual screening," Diabetic Medicine, vol. 12, no. 7, pp. 622-627, 1995.

[16] S. Stanická, K. Vondra, T. Pelikánová, P. Vlček, M. Hill, and V. Zamrazil, "Insulin sensitivity and counter-regulatory hormones in hypothyroidism and during thyroid hormone replacement therapy," Clinical Chemistry and Laboratory Medicine, vol. 43, no. 7, pp. 715-720, 2005.

[17] P. Mitrou, S. A. Raptis, and G. Dimitriadis, "Insulin action in hyperthyroidism: a focus on muscle and adipose tissue," Endocrine Reviews, vol. 31, no. 5, pp. 663-679, 2010.

[18] US Preventive Services Task Force, "Screening for thyroid disease: recommendation statement," Annals of Internal Medicine, vol. 140, no. 2, pp. 125-127, 2004.

[19] E. Güney, B. Efe, A. Akalın, M. N. Kebapçı, and E. Erenoğlu, "Thyroid disease in diabetes mellitus," Turkish Journal of Endocrinology and Metabolism, vol. 3, pp. 119-122, 1999.

[20] R. W. Holl, B. Böhm, U. Loos, M. Grabert, E. Heinze, and J. Homoki, "Thyroid autoimmunity in children and adolescents with type 1 diabetes mellitus," Hormone Research, vol. 52, no. 3, pp. 113-118, 1999. 


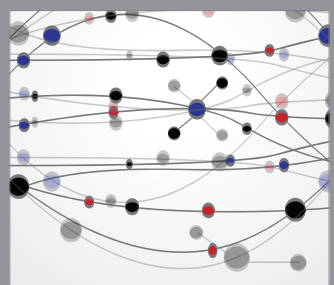

The Scientific World Journal
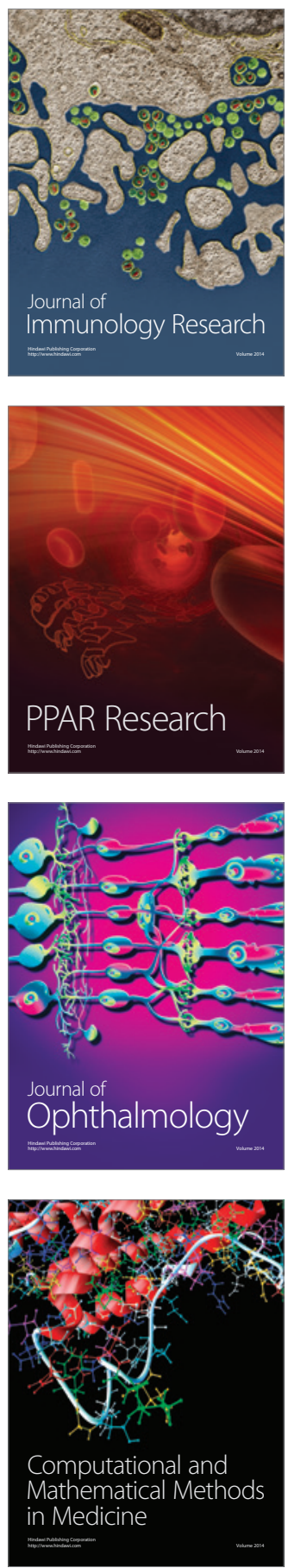

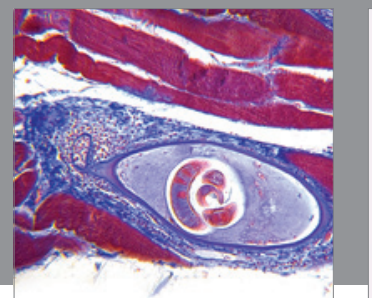

Gastroenterology

Research and Practice
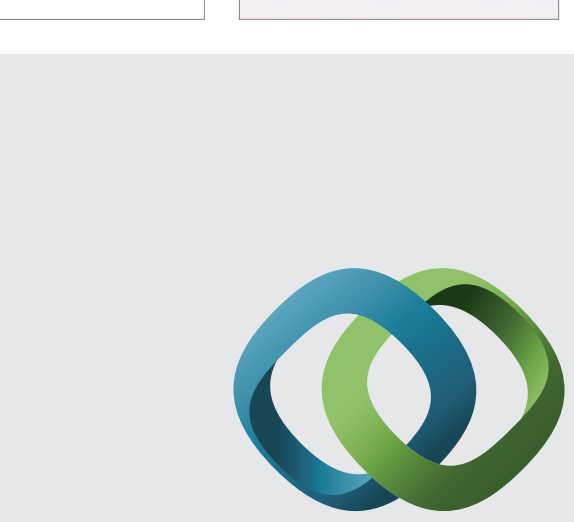

\section{Hindawi}

Submit your manuscripts at

http://www.hindawi.com
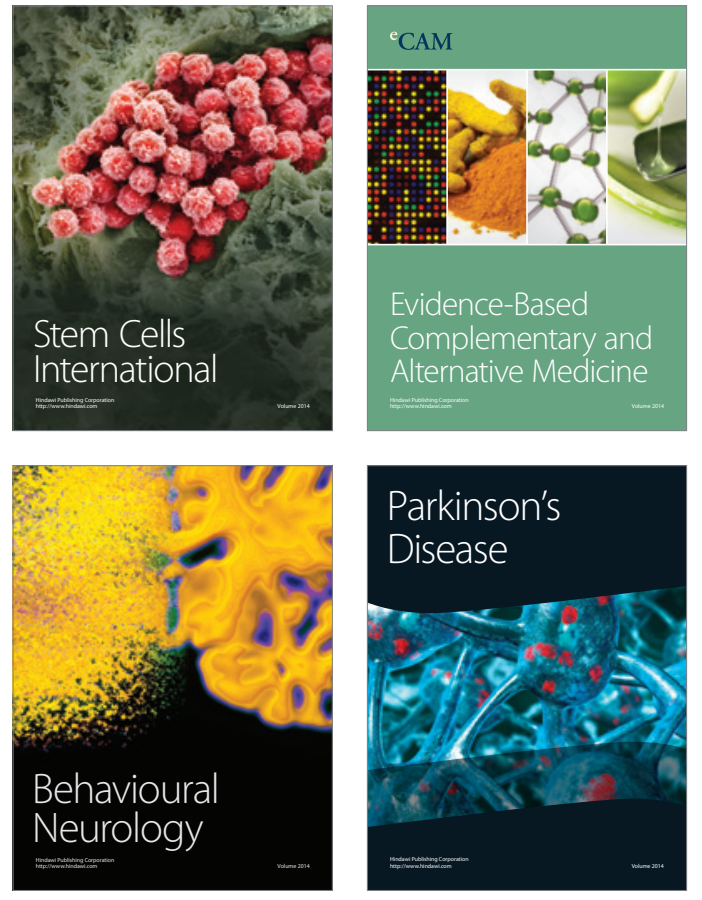
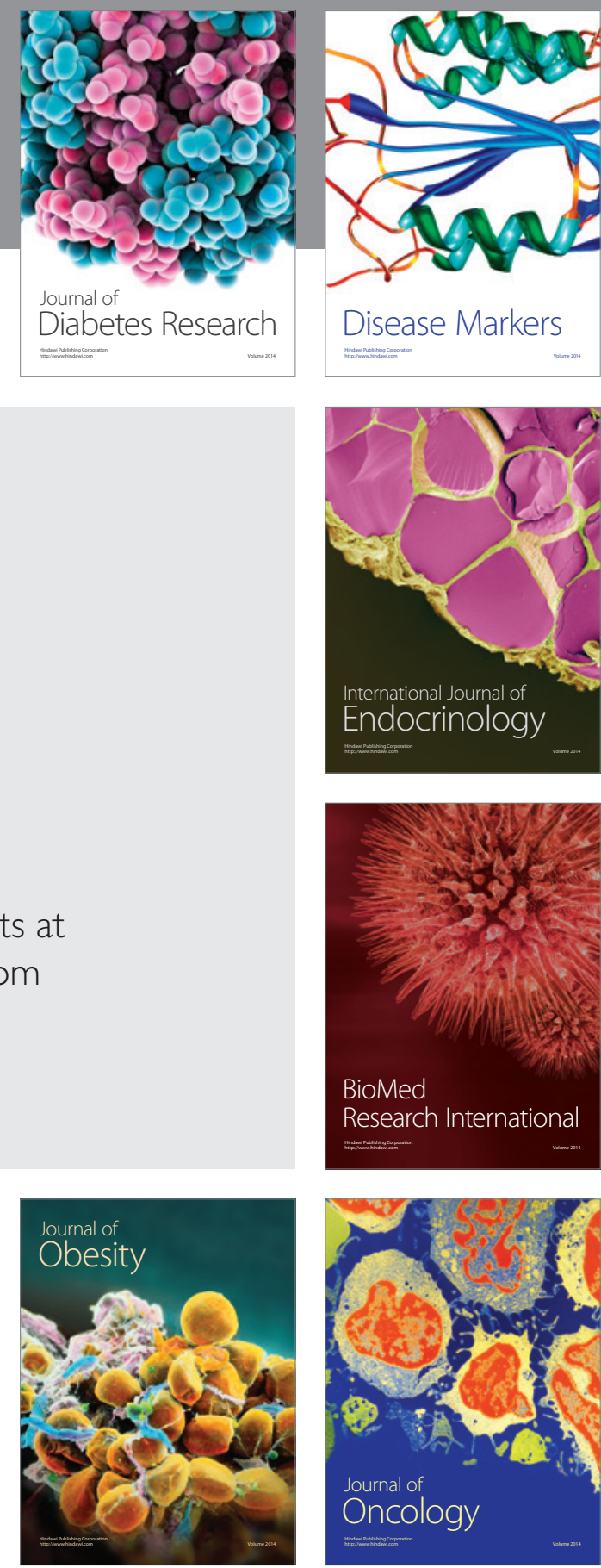

Disease Markers
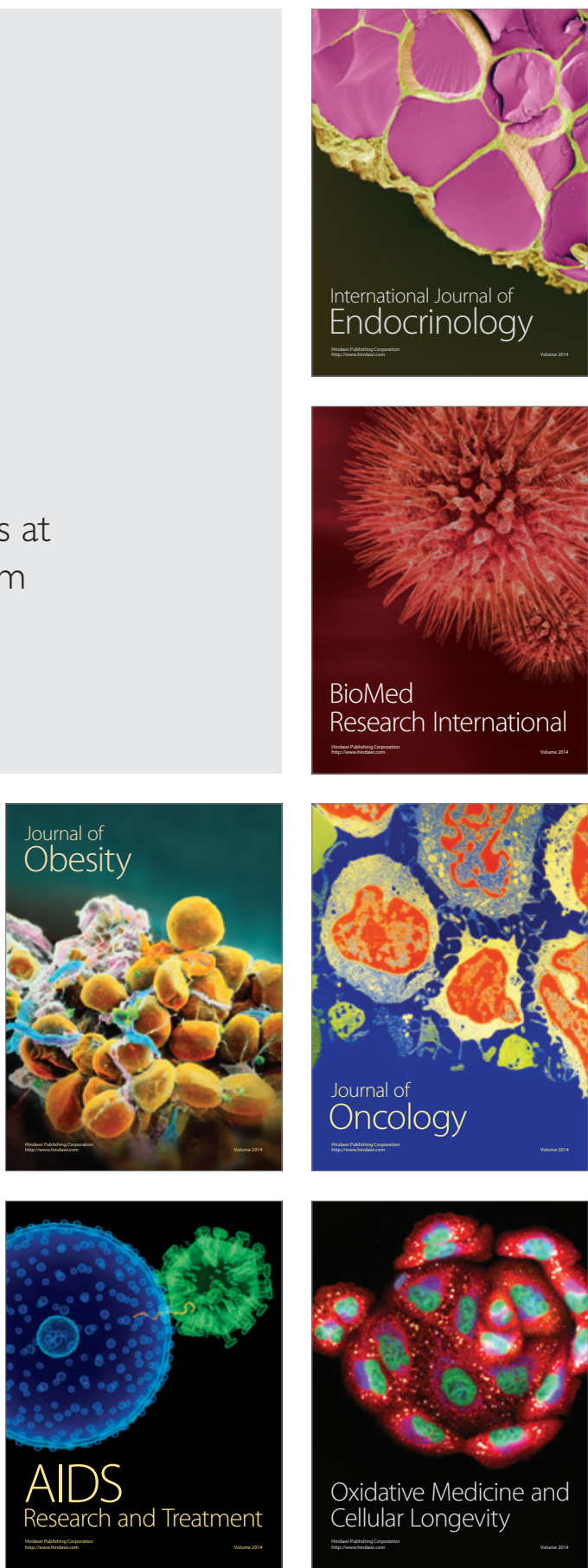